\title{
Research
}

\section{Who Benefits from Recreational Use of Protected Areas?}

\author{
$\underline{\text { Josephine E. Booth }}^{1,2}, \underline{\text { Kevin J. Gaston }}^{1}$, and $\underline{\text { Paul R. Armsworth }}^{1,3}$
}

\begin{abstract}
Public support for protected areas depends, in part, upon clear demonstrations of the importance of the ecosystem services provided by these areas. However, only a limited number of studies have examined the value of protected areas in providing these services, and even less work has assessed how equitably these benefits are distributed across society. We used on-site surveys to characterize people who derived recreational benefit from a set of areas in the United Kingdom that were originally protected for their conservation value. We found that an unrepresentative subset of society enjoyed this benefit. Site visitor populations were biased towards older people and men, and minority groups were starkly underrepresented, comprising only $1 \%$ of overall visitors. When the characteristics of visitors were examined, the more privileged sectors of society were found to have received disproportionate benefits. These biases persisted across weekday and weekend visits and whether sites were considered altogether or individually. Conservation goals will only be met if broad public support for the natural environment is engaged and maintained, for example, through nature recreation. However, our results suggest that at present a worrying disconnect exists between public conservation efforts and much of society.
\end{abstract}

Key Words: Ecosystem services; protected areas; recreation; recreational benefits; Sites of Special Scientific Interest; SSSI; social inclusion; surveys

\section{INTRODUCTION}

Protected areas are central to efforts to conserve biodiversity. In addition, these areas provide diverse benefits to people (Ingraham and Foster 2008, Eigenbrod et al. 2009). Measuring the ecosystem service benefits (Millennium Ecosystem Assessment 2005) provided by protected areas has been identified as a question of immediate policy concern (Sutherland et al. 2006, National Audit Office 2008).

Over 100,000 protected areas worldwide cover more than $12 \%$ of the Earth's land surface (Brooks et al. 2004, Chape et al. 2005). Areas originally protected to meet narrow conservation objectives are now expected to fulfill a much wider variety of ecological, economic, and social functions (Holdgate 1992). For example, areas in the United Kingdom (UK) originally protected because they contained specific species or habitats of conservation interest are now being evaluated based not only on their ecological success but also on their ability to provide recreation services, educational opportunities, and other means of resource utilization (Gaston et al. 2006). Conversely, areas in the United States originally designated for recreation because of their scenery and landscape are now being evaluated for their ability to support biodiversity conservation (Dunk et al. 2006).

Although ecosystem services from protected areas possess some degree of public-good characteristics (namely non-rivalry and non-excludability; Kolstad 2000), many of these benefits are spatially localized. Therefore, just as for public schools, public swimming pools, and other spatially localized public goods, some sectors of society potentially enjoy greater benefits from protected areas (Tiebout 1956, Oates 2006) because they have more ready access (either they live nearer or they have better access to private vehicles). To date, assessments of the performance of protected areas have emphasized aggregate measures of value such as total recreational access (Hein et al. 2006, Önal and Yanprechaset 2007) or overall economic value 
(Scarpa et al. 2000, Naidoo and Ricketts 2006, Troy and Wilson 2006). However, people experience ecosystem services over different spatial and temporal scales. When valuing such services, it is essential to consider how the benefits are distributed and whether this distribution is equitable across society. Such topics have thus far received little attention (Tarrant and Cordell 1999, Floyd and Johnson 2002). Valuation estimates for ecosystem services have also been found to differ between stakeholder groups. For example, Bowker and Leeworthy (1998) noted differences in the preferences of various ethnic groups for outdoor recreation, and Fa et al. (2002) showed that ethnicity was a factor in determining preferences in bushmeat consumption on Bioko Island in Equatorial Guinea.

Understanding who benefits from protected areas and who does not is the first step to widening participation and engagement with nature conservation across society; obstacles that prevent people from enjoying these benefits can then be identified and removed (Lee and Scott 2001, Wesely and Gaarder 2004). In the face of changing social preferences, proactive measures to engage society in conservation are needed if we are to maintain broad support for protected areas (Pergams and Zaradic 2006). Such support is particularly important given that most protected areas are funded at least in part by the public purse, through either direct investment or foregone tax revenue.

To determine how evenly ecosystem services from protected areas are distributed, we focused on recreation. Recreation is a direct-use value of an ecosystem (Hein et al. 2006). Recent efforts to incorporate recreation benefits into conservation planning have focused on access-based measures (Ruliffson et al. 2002, Chan et al. 2006, Önal and Yanprechaset 2007). However, we have instead used on-site surveys to examine the actual uptake of recreation opportunities. Our surveys focused on the lowest of institutional scales: the individual, household, or family/group level (Hein et al. 2006). We assessed who was deriving recreation benefit from protected areas and how representative these visitors were of the wider society over local, regional, and national scales.

\section{METHODS}

\section{Data collection}

We have surveyed visitors to a sample of the Sites of Special Scientific Interest (SSSIs) in England as a case study. The SSSI network is a central component of UK conservation policy, consisting of over 4100 sites covering in excess of a million hectares or over 7\% of England's land area (English Nature 2003). SSSIs are under diverse ownership but have nonetheless been designated by the UK government to protect their floral, faunal, geological, or physiographical features of particular conservation interest (Bishop et al. 1997). While SSSIs were originally designated purely for conservation purposes, these areas are increasingly seen as vehicles for delivering public benefits from the countryside. For example, the core objectives of the agency responsible for overseeing the conservation of these sites, Natural England, include increasing the number, diversity, and frequency of people enjoying the natural environment (Natural England 2006).

We conducted on-site paper-based questionnaire surveys with visitors to 13 of the best visited SSSIs in the Yorkshire and Humberside regions of England. The questionnaire was previously piloted on three separate occasions in a protected area away from the main study region. Any questions that received a low response rate or that people found difficult to answer were removed or altered. Sites varied in size, location, and habitat, thus giving a cross-section of the SSSIs in the study region (Table 1). Sites also varied in their proximity to urban areas: some were on the edges of large towns (e.g., Doncaster) whereas others were more rural. We administered questionnaires on weekdays and weekends (days varied from site to site) from June through to September 2006, but only during daylight hours and in fair weather (38 survey days in total). Questionnaires were administered at entry/exit points to the sites. People were approached as they left the site; after one survey was finished, the interviewer would approach the next potential interviewee. A total of five interviewers were employed, with a consistent procedure being used for both approaching people and administering the questionnaires. Visitors were guided through the questions by the interviewer, with the survey taking between five and ten minutes to complete. Each 
Table 1. Survey sites, numbers of individuals involved, numbers of questionnaires returned, site areas, and 25 th and 50th percentiles of distances traveled.

\begin{tabular}{|c|c|c|c|c|c|c|c|}
\hline \multirow[t]{2}{*}{ Site } & \multicolumn{2}{|c|}{ No. of individuals } & \multicolumn{2}{|c|}{ No. of questionnaires } & \multirow[t]{2}{*}{$\begin{array}{c}\text { Area } \\
\text { (ha) }\end{array}$} & \multicolumn{2}{|c|}{$\begin{array}{l}\text { Distances traveled } \\
(\mathrm{km})\end{array}$} \\
\hline & Weekdays & Weekends & Weekdays & Weekends & & $\begin{array}{c}25^{\text {th }} \\
\text { percentile }\end{array}$ & $50^{\text {th }}$ percentile \\
\hline Brockadale & 41 & 32 & 19 & 18 & 59 & 5.3 & 6.1 \\
\hline $\begin{array}{l}\text { Cow and Calf } \\
\text { Rocks }\end{array}$ & 64 & 77 & 21 & 24 & 230 & 8.9 & 15.9 \\
\hline Denaby Ings & 26 & 40 & 17 & 21 & 25 & 4.7 & 6.3 \\
\hline $\begin{array}{l}\text { Fairburn and } \\
\text { Newton Ings }\end{array}$ & 26 & 41 & 17 & 18 & 174 & 6.9 & 12.1 \\
\hline Filey Brigg & 38 & 49 & 20 & 20 & 28 & 55.0 & 101.7 \\
\hline $\begin{array}{l}\text { Flamborough } \\
\text { Head }\end{array}$ & 60 & 82 & 19 & 26 & 327 & 42.0 & 94.8 \\
\hline $\begin{array}{l}\text { Forge Valley } \\
\text { Woods }\end{array}$ & 31 & 49 & 16 & 20 & 89 & 4.7 & 5.8 \\
\hline Potteric Carr & 21 & 42 & 14 & 19 & 118 & 3.7 & 6.1 \\
\hline Sandall Beat & 33 & 31 & 17 & 20 & 66 & 1.9 & 2.4 \\
\hline $\begin{array}{l}\text { Skipwith } \\
\text { Common }\end{array}$ & 27 & 45 & 15 & 18 & 295 & 3.9 & 6.0 \\
\hline $\begin{array}{l}\text { Sprotbrough } \\
\text { Flash }\end{array}$ & 32 & 28 & 16 & 14 & 81 & 2.3 & 4.8 \\
\hline Spurn Head & 66 & 78 & 23 & 26 & 157 & 70.0 & 112.7 \\
\hline Tophill Low & 0 & 36 & 0 & 17 & 35 & 11.1 & 18.0 \\
\hline Totals & 465 & 630 & 214 & 261 & - & - & - \\
\hline
\end{tabular}

survey included 20 closed-form questions. However, this paper analyzes only the subset of the questions concerning visitor age, gender, ethnicity, and home postcodes (equivalent to full U.S. zip codes). A sample questionnaire is presented in Appendix 1. Our results do not depend on the imposition of a particular economic valuation model for recreation, but they would be particularly compatible with travel-cost or stated-preference approaches, relying as they do upon on-site visitor surveys.

\section{Reference populations}

We examined whether visitors to these 13 sites were representative of society at large using four reference populations spanning a range of spatial scales. First, we compared the diversity of visitors to the populations of Yorkshire and the UK. Then, because many individuals had not travelled far to visit the sites, we compared the visitors at each individual site to the local population in the surrounding area. We identified local reference 
populations by drawing circular buffers around each site. As the distances travelled to each site varied substantially, we defined our local reference population based on the $25^{\text {th }}$ and $50^{\text {th }}$ percentiles of distances travelled by individuals to get to the site (Table 1).

We collated data from the 2001 UK Population Census for each of the four reference populations to establish the age, gender, and ethnicity of wider populations across local, regional, and UK scales.

To determine how representative visitors were of the diversity of UK households more generally, we used Mosaic UK (Experian UK, http://www.experi an.co.uk/business-strategies/mosaic-uk-2009.html ), a commercially available geodemographic database (Harris et al. 2005). This database identifies broad types of households that make up UK society. The version of Mosaic UK used in this analysis applied a hierarchical cluster analysis to 430 social, economic, and demographic variables that describe households, with variables being chosen for their explanatory power (Webber 2004). Fifty-four per cent of the variables entered into this cluster analysis were derived from the 2001 UK Population Census; the remainder came from a number of other sources, including Experian's own lifestyle surveys, the edited electoral roll, consumer credit activity, and house price data. The classification assigns each household to one of 11 groups and 61 subclasses that share similar characteristics; however, we used only the grouplevel classifications for our analyses. The results of the clustering analyses have been ground-truthed with over 15,000 visits to UK neighborhoods. Experian has also collected additional independent survey data on the identified categories of households (concerning, for example, their likelihood to undertake outdoor recreation) that are independent of the data used to inform the initial clustering. In our study, we used a single classification for each full UK postcode (around 15-20 households) and used postcodes to associate visitors with one of the 11 Mosaic groups. Of course, not every household within a postcode will conform to the broad categorization provided by Mosaic. However, geodemographic databases like Mosaic not only provide much greater resolution than that available in the UK Census data but also give a summary of multidimensional information on household characteristics that would have been too time consuming to obtain and analyze through direct questions in our own survey. Mosaic has previously been used in diverse applications both in public policy design and in the private sector (Webber 1985, Farr and Webber 2001, Williamson et al. 2005). However, such geodemographic tools have not often been applied to environmental problems (but see Barbosa et al. 2007 and Fuller et al. 2008 for applications in an urban context).

\section{Data analysis}

First, we analyzed the sample of visitors from all sites combined to establish how representative visitors were of regional and UK populations. We carried out one-way chi square tests for gender (male/female) and ethnicity (white/black and ethnic minority). Although ethnicity data were collected based upon census data groups, the lack of people describing themselves as belonging to black and ethnic minorities meant we could categorize the data into just two groups for analyses. We also analyzed the representativeness of the sample at all sites by age and household type using chi square tests and correlation coefficients. Then we analyzed the age, ethnicity, gender, and household type of visitors to individual sites and compared this with the local reference populations $\left(25^{\text {th }}\right.$ and $50^{\text {th }}$ percentiles of distance traveled as previously described) and to the populations of Yorkshire and the UK using chi square tests, t-tests, and correlations. For all analyses, we transformed any data that did not meet assumptions of normality. Whenever this transformed data did not meet assumptions of normality, nonparametric tests were used on the untransformed data.

\section{RESULTS}

In total, 475 questionnaires covering 1095 people were completed across the 13 sites (Table 1), and we collected 471 postcodes that could be mapped to Mosaic data. The discrepancy in the numbers of postcodes collected and questionnaires completed resulted from a combination of incorrect postcodes, multiple postcodes on a single questionnaire (when people from different households were in the same car), and no postcodes (when people declined to provide the information).

People were also asked what they intended to do while visiting the SSSI (see Appendix 1). Some people gave more than one activity (e.g., walking as well as having a picnic), resulting in 619 
responses for the 475 questionnaires. Walking was the most popular activity, with $40 \%$ of respondents choosing this option. Twenty-six per cent of visitors stated that they were walking their dog and 19\% that they were birdwatching (as a number of the sites are good for birding or have bird blinds). A further $4 \%$ of visitors were having picnics, and less than $1 \%$ were there to cycle. The remaining $11 \%$ of visitors (the "Other" responses) were undertaking activities such as photography, rock climbing, or fishing. Although the activities recorded in the survey likely vary in their compatibility with the ecological goals of site protection, even low levels and intensities of recreation use have been known to damage such sites (Reed and Merenlender 2008). Encouraging the recreational use of sites involves trade-offs: for a discussion of the trade-offs between the short-term ecological costs due to damaging recreational activities and the long-term ecological gains resulting from reconnecting society with nature, see Booth et al. (2009).

\section{All sites conbined}

Those enjoying recreation benefits from our focal protected areas were not representative of the wider Yorkshire and UK populations along any of the four axes of social diversity (Table 2). We found a significant bias towards male visitors compared to both the regional and national populations. For ethnicity, we found a strong bias towards whites when compared to the ethnic mix of the population. Indeed, only nine of the individuals surveyed $(0.008 \%)$ described themselves as being from black or ethnic minorities.

The age of visitors showed great disparity when compared with the regional and national populations (Table 2). The 56-65 age group was greatly overrepresented among site visitors, whereas only very low numbers of visitors were in the 16-25 age group. Consequently, the correlations between the age distribution of the sample of visitors and the wider populations of Yorkshire and the UK were not significant and explained little of the variation in the sample (Yorkshire: $r=0.067, P>$ 0.05; UK: $r=0.078, P>0.05)$.

Visitors to SSSIs were also unrepresentative of the wider population when analyzed in terms of broader household characteristics using the Mosaic data, which integrate diverse social, economic, and demographic variables. The basic trend in the analysis of our survey was that the more affluent groups within society benefited disproportionately from recreational use of protected areas, while the less affluent groups were generally underrepresented (Table 2). Again, these biases meant that the proportions of each Mosaic grouping among visitors were poorly correlated with their prevalence in the wider population (Yorkshire: $r=0.34, P>0.05$; UK: $r=0.05, P>0.05)$. Additional information collected by Experian on household characteristics (identified by the clustering analysis) enabled us to characterize further the living circumstances of households that benefit disproportionately from recreational use. The tendency to participate in recreation in protected areas is negatively correlated with overall deprivation; i.e., the more deprived households are underrepresented (Yorkshire: $r=$ $-0.66, P=0.027$; UK: $r=-0.96, P<0.001)$. In addition, the under- or overrepresentation observed in Mosaic groups correlated with the average number of private cars per household (Yorkshire: $r$ $=0.71, P=0.014$; UK: $r=0.88, P<0.001)$ and the percentage of households that enjoy recreational hiking and walking (Yorkshire: $r=0.65, P=0.03$; $\mathrm{UK}: r=0.88, P<0.001)$.

It is possible that some of these biases could have resulted from the aggregation of weekday and weekend visitors, because some sectors of society (such as retirees) may have more leisure time during weekdays than those of working age. To explore this possibility, we repeated all of the above analyses separately for weekday and weekend visitors. Similar biases were found in the gender, ethnicity, age, and socioeconomic characteristics of recreational visitors to protected areas (Table 2). Both the weekday and weekend samples were biased in terms of gender and ethnicity, although this bias was weaker than in the aggregated sample. Biases in age were similarly less marked than in the aggregated sample; however, the weekend data displayed greater evidence of bias than that of weekdays. The results for socioeconomic characteristics also showed greater bias for weekends than weekdays. Overall, the weekend data showed a much stronger bias towards the more privileged groups. Consequently, correlations of age and socioeconomic characteristics had weak explanatory power and were not statistically significant for the aggregrated results. 
Table 2. Chi square tests on the sample population vs. the populations of Yorkshire and of the UK. Data for all the sites were analyzed for all days combined, for weekends, and for weekdays. One-way tests were performed for ethnicity and gender.

\begin{tabular}{|c|c|c|c|c|c|c|c|c|c|c|c|c|c|}
\hline & \multirow[b]{3}{*}{ d.f. } & \multicolumn{4}{|c|}{ All days combined } & \multicolumn{4}{|c|}{ Weekend } & \multicolumn{4}{|c|}{ Weekdays } \\
\hline & & \multicolumn{2}{|c|}{ Yorkshire } & \multicolumn{2}{|c|}{ UK } & \multicolumn{2}{|c|}{ Yorkshire } & \multicolumn{2}{|c|}{ UK } & \multicolumn{2}{|c|}{ Yorkshire } & \multicolumn{2}{|c|}{ UK } \\
\hline & & $\chi^{2}$ & $P$ & $\chi^{2}$ & $P$ & $\chi^{2}$ & $P$ & $\chi^{2}$ & $P$ & $\chi^{2}$ & $P$ & $\chi^{2}$ & $P$ \\
\hline Gender (male) & 1 & 12.1 & $<0.001$ & 11.3 & $<0.001$ & 5.8 & $<0.05$ & 5.4 & $<0.05$ & 6.27 & $<0.05$ & 5.89 & $<0.05$ \\
\hline $\begin{array}{l}\text { Ethnicity (ethnic } \\
\text { minority) }\end{array}$ & 1 & 55.4 & $<0.001$ & 70.2 & $<0.001$ & 42.2 & $<0.001$ & 50.8 & $<0.001$ & 31.24 & $<0.001$ & 37.58 & $<0.001$ \\
\hline Age & 6 & 217.0 & $<0.001$ & 231.0 & $<0.001$ & 151.4 & $<0.001$ & 156.4 & $<0.001$ & 109.2 & $<0.001$ & 109.2 & $<0.001$ \\
\hline $\begin{array}{l}\text { Socioeconomic } \\
\text { status }\end{array}$ & 10 & 49.9 & $<0.001$ & 55.1 & $<0.001$ & 161.2 & $<0.001$ & 136.5 & $<0.001$ & 23.6 & $<0.01$ & 34.8 & $<0.001$ \\
\hline
\end{tabular}

\section{Individual sites}

The majority of visitors travelled only very short distances to sites (Fig. 1), with 55\% travelling less than $16 \mathrm{~km}$ (10 miles). It is therefore possible that while visitors to these sites were not representative of the populations of Yorkshire and the UK, they may have been representative of the local populations surrounding the individual sites. We tested this possibility for all four axes of social diversity, carrying out four comparisons for each site (visitors to the site against the $25^{\text {th }}$ percentile local population, the $50^{\text {th }}$ percentile local population, the Yorkshire population, and the UK population). With such analyses of gender and ethnicity, the issue of statistical power must be considered. Sample sizes at the individual site level ranged from 36 to 144 individuals (Table 1), which gave varying degrees of power for the analyses.

For gender, a clear bias towards male visitors was found at the aggregated site level, but this signal was not as marked when individual sites were examined. Indeed, this bias was only marginally significant for all the sites except one (Denaby Ings), which gave significant results for gender across all four reference populations (Appendix 2). These results would indicate either that larger sample sizes are needed at the site level or that there is no effect locally.
In terms of ethnicity, 11 of the 13 sites (all but Cow and Calf Rocks and Tophill Low) showed significant differences when compared with the Yorkshire and UK populations (Appendix 3). However, such differences were not found at the more localized $25^{\text {th }}$ and $50^{\text {th }}$ percentile levels of distance traveled for the majority of sites. This disparity is likely to be a result of the more localized populations having fewer members of black and ethnic minorities than the regional and UK populations. The local reference populations of the sites that received visitors from the surrounding area naturally reflect the ethnic makeup of those areas, whereas those sites that attracted people from long distances gave either significant or marginally significant results when compared with the $50^{\text {th }}$ percentile. Spurn Head illustrates this general result, with the local reference population being ethnically the most similar to the sample collected on site and the UK population the most dissimilar (percentages of black and ethnic minorities on site, $0.69 \% ; 25^{\text {th }}$ percentile, $2.6 \% ; 50^{\text {th }}$ percentile, $4.15 \%$; in Yorkshire, 6.52\%; UK, 7.88\%).

When comparing the ages of visitors at the individual sites with the reference populations, no consistent improvement was found in the representativeness of those enjoying recreation benefits. Correlations gave a mixture of positive and negative results, but none were statistically 
Fig. 1. Histogram showing frequency of individual visits vs. distance traveled per visit for all 13 sites.

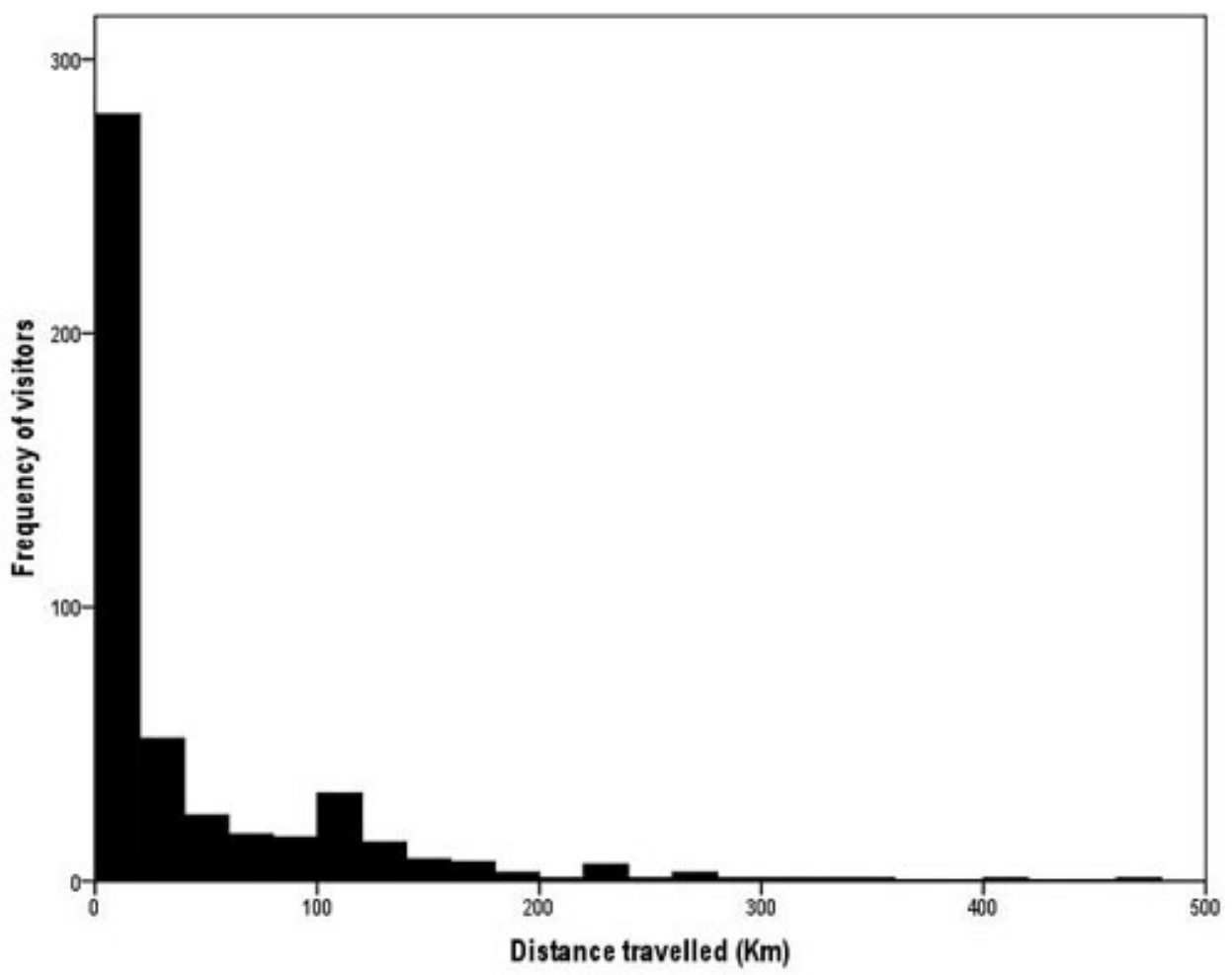

significant and the $r^{2}$ values were generally low. Figs. 2-5 are box and whisker plots showing the distributions of residuals of age (i.e., observed minus expected values based on the reference population) across the sites in each age class for each of the four reference populations $\left(25^{\text {th }}\right.$ percentile, $50^{\text {th }}$ percentile, Yorkshire, and the UK). Positive values indicate that a given group is overrepresented at that site relative to their presence in the reference population. Negative values indicate underrepresentation. Interquartile ranges are indicated in the plot for each age group, and asterisks indicate outliers in the data. Across all sites and reference population choices, the 56-65 age group was consistently overrepresented $\left(25^{\text {th }}\right.$ percentile $t_{(11)}=3.82, P=0.002 ; 50^{\text {th }}$ percentile $t_{(11)}$ $=4.40, P=0.001$; Yorkshire $t_{(11)}=4.25, P=0.001$; $\left.\mathrm{UK} t_{(11)}=4.35, P=0.001\right)$, and the 16-25 age group was always underrepresented (25th percentile $t_{(11)}$ $=-1.76, P=0.103 ; 50$ th percentile $t_{(11)}=-2.89, P$ $=0.013$; Yorkshire $t_{(11)}=-4.12, P=0.001 ; \mathrm{UK} t_{(11)}$ $=-3.96, P=0.002)$. However, the latter effect was less evident at the most local scale. This overall bias in ages, which persisted across all scales of analysis, explains why correlations with the reference populations remained weak.

All correlations of visitor numbers with proportions of each Mosaic group in the four reference populations were positive, but only some were statistically significant (Table 3). Fig. 6 illustrates the outcomes of these correlations. For each individual site, we have graphed the minimum explanatory power $\left(r^{2}\right)$ of the various correlations of visitors with the local reference populations (i.e., populations living within the $25^{\text {th }}$ and $50^{\text {th }}$ percentiles of distances traveled) against the maximum $r^{2}$ value of the analogous correlations of site visitors with the regional and national populations. For ease of reference, we have also marked on the vertical axis the equivalent maximum obtained when pooling the visitor samples from all sites and comparing the pooled value to that of Yorkshire and the UK. Only 11 of the 13 site data 
Fig. 2. Residuals of age groups for the $25^{\text {th }}$ percentiles of distance traveled.

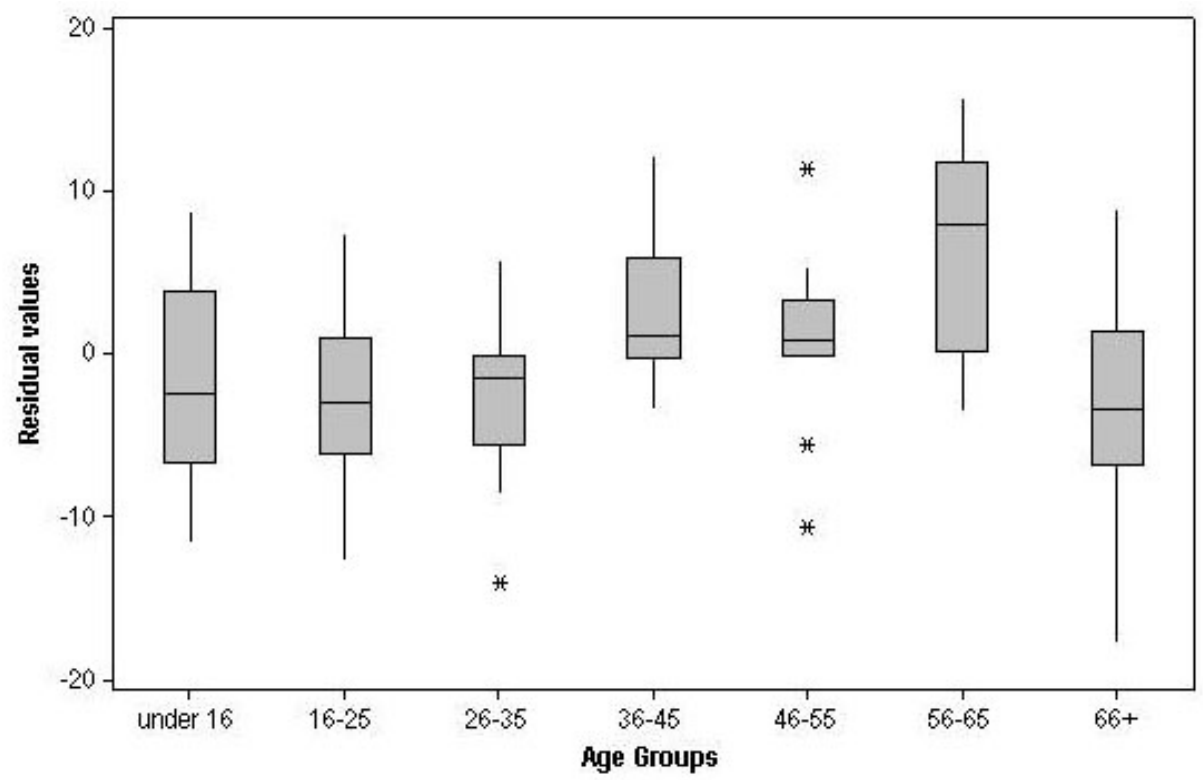

points are graphed in Fig. 6: the remaining two sites were omitted here because they were analyzed using Spearman's Rank correlation (since their data were not normally distributed even when transformed; Table 2). When comparing the socioeconomic composition of visitors at individual sites to that of the populations of Yorkshire and the UK, the explanatory power of correlations was increased from that obtained by pooling the samples of visitors at all sites. This suggests that pooling samples from across the diverse protected areas masked the correlations that were evident at the site level. As seen in Fig. 6, the explanatory power of correlations of all individual sites against Yorkshire and the UK was greater than that obtained when pooling visitors across the sites; i.e., the values for most of the individual sites fell further up the vertical axis than the value for all sites combined (shown on the axis itself).

As most visitors did not travel far, we might expect that for a given site the distribution of household types within the sample would more closely match that of the surrounding area than of the regional or national population. Were we to apply this logic strictly, we would expect that the explanatory power for the sample would be most representative of (a) the closest reference population $\left(25^{\text {th }}\right.$ percentile of distance travelled), then (b) the next nearest $\left(50^{\text {th }}\right.$ percentile of distance travelled), then (c) the Yorkshire population, and finally least representative of (d) the UK as a whole (i.e., $a>b>c>d$ ). Only two sites, Skipwith Common and Denaby Ings, fit this pattern (Table 3). A less stringent definition would be that the explanatory power for both the $25^{\text {th }}$ and $50^{\text {th }}$ percentile reference populations would be greater than that for Yorkshire and the UK (i.e., a, b >c,d). Only one additional site meets this criterion: Sandall Beat. This localization criterion is equivalent to asking which sites fall below the 45 degree line in Fig. 6. Those sites not showing evidence of localization (those falling above the 45 degree line) include the coastal sites Flamborough Cliffs, Spurn Head, and Filey Brigg, all of which attract visitors from across a broad area (Table 1) and by our definitions encompass a very large populace. 
Fig. 3. Residuals of age groups for the $50^{\text {th }}$ percentiles of distance traveled.

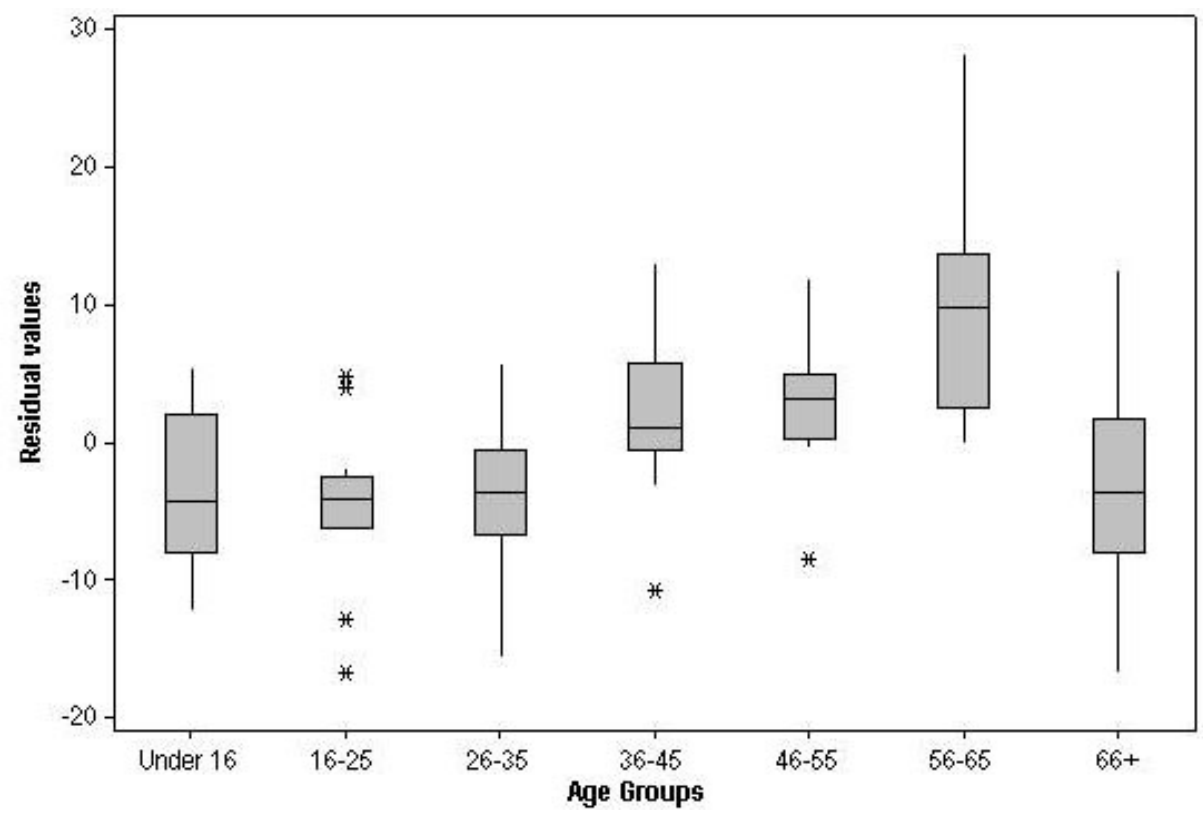

\section{DISCUSSION}

The need for further research into the valuation of ecosystem services has been widely recognized (Balmford et al. 2002, Carpenter et al. 2006), but studies examining who actually benefits from ecosystem services and whether these benefits are distributed equitably across society lag even further behind. Without knowing who experiences benefits from protected areas, it is not possible to gain accurate estimates of the value of these services or to resolve conflicts concerning their usage. We addressed this question in the particular context of legally protected areas and focused on recreation services. Repeating the exercise for other ecosystem services that have local public good characteristics, such as managing upstream habitats to mitigate flood effects on downstream households, would also be worthwhile. However, ecosystem services vary in the scales over which they are experienced, and some services, such as the contributions to climate regulation from carbon sequestration, are much more diffusely distributed.

Our results revealed striking biases in who enjoys recreation benefits from SSSIs across all four dimensions of social diversity as well as across local, regional, and national scales. Visitors to the protected areas were not representative of wider society in terms of gender, ethnicity, age, or socioeconomic characteristics.

The underrepresentation of women recreationalists visiting our sites corresponds with the results of visitor surveys conducted in other locations, although many of those were conducted in an urban context (e.g., Ho et al. 2005). Concerns about security and personal safety are common reasons for women being underrepresented among outdoor recreationalists in both urban and wilderness contexts (Shaw 1994, Mehta and Bondi 1999, Krenichyn 2006, Shores et al. 2007). The protected areas we studied vary in their degrees of isolation, and security concerns would certainly be important at some sites; indeed, it is perhaps telling that single male visitors were overrepresented in our sample compared to single female visitors.

The distribution of recreation benefits from our sites is also very clearly biased with respect to ethnicity. It has been recognized that ethnic groups are underrepresented in the British countryside (e.g., Black Environment Network 2003), and a number of agencies and organizations have been striving to 
Fig. 4. Residuals of age groups for Yorkshire.

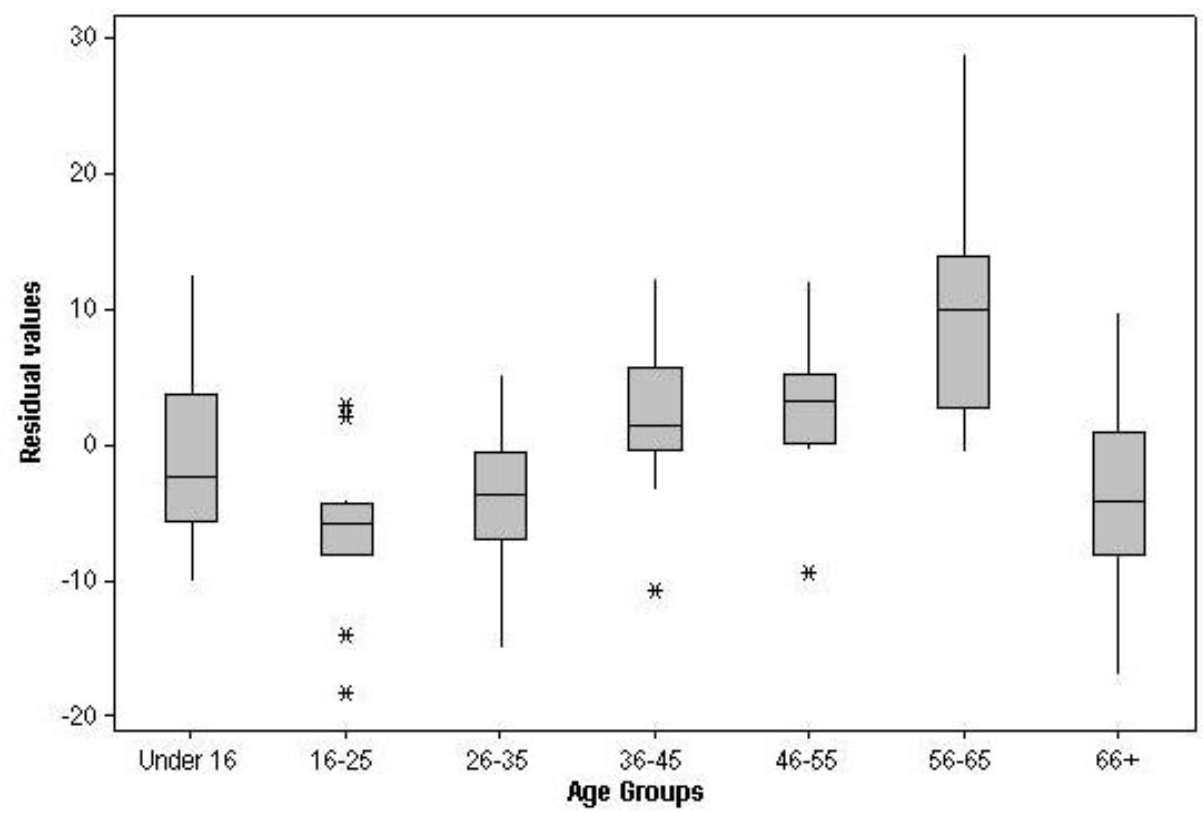

remedy this situation. However, we found that less than $1 \%$ of visitors in our survey were from black and ethnic minority groups (a lower percentage than that found by an earlier study [Countryside Agency 2005]), even though these groups constitute much larger percentages of the local, regional, and national populations. These minority individuals were effectively visiting just two sites: Spurn Head, which attracts people from a wide area, and Cow and Calf Rocks, which is near centers of very diverse populations. Site by site analysis showed that although some sites had visitor distributions that were similar to local populations in terms of ethnicity, the visitors to all but these two sites were significantly different from regional and national populations. In the past, it has been assumed that those from ethnic minorities simply had no interest in the countryside (Black Environment Network 2003), but studies conducted in both the UK and the USA have found that ethnic minorities face multiple constraints to outdoor recreation, including lack of income, familiarity, opportunity, and transportation as well as fear of discrimination (Gómez 2002, Edwards and Weldon 2006, Shores et al. 2007). It is also clear that different ethnic groups have differing preferences in terms of outdoor recreation spaces, with some ethnic minorities preferring more developed recreation areas (with toilet facilities, for example) but white visitors preferring wilder areas (Virden and Walker 1999, Ho et al. 2005).

In terms of broader household characteristics, our protected areas provide disproportionate recreation benefits to the more affluent and less deprived social groups. We observed some improvement in the representativeness of visitors in terms of their Mosaic classification when we moved to the individual site scale, but clear biases persisted for many sites. This pattern of the more deprived groups missing out on protected area benefits may be partly attributable to access constraints, because social groups that have the use of private cars are more likely to visit remote sites. In a related study in the nearby city of Sheffield, Barbosa et al. (2007) found that access to public and private green spaces within cities also showed strong associations with the household characteristics surveyed by Mosaic.

Finally, our results demonstrate a strong age bias in the visitors across all sites and all scales. Young adults (16-25) are disproportionately underrepresented, whereas those in the 56-65 age group are overrepresented. This bias could be symptomatic of young people being disengaged with outdoor 
Fig. 5. Residuals of age groups for the UK.

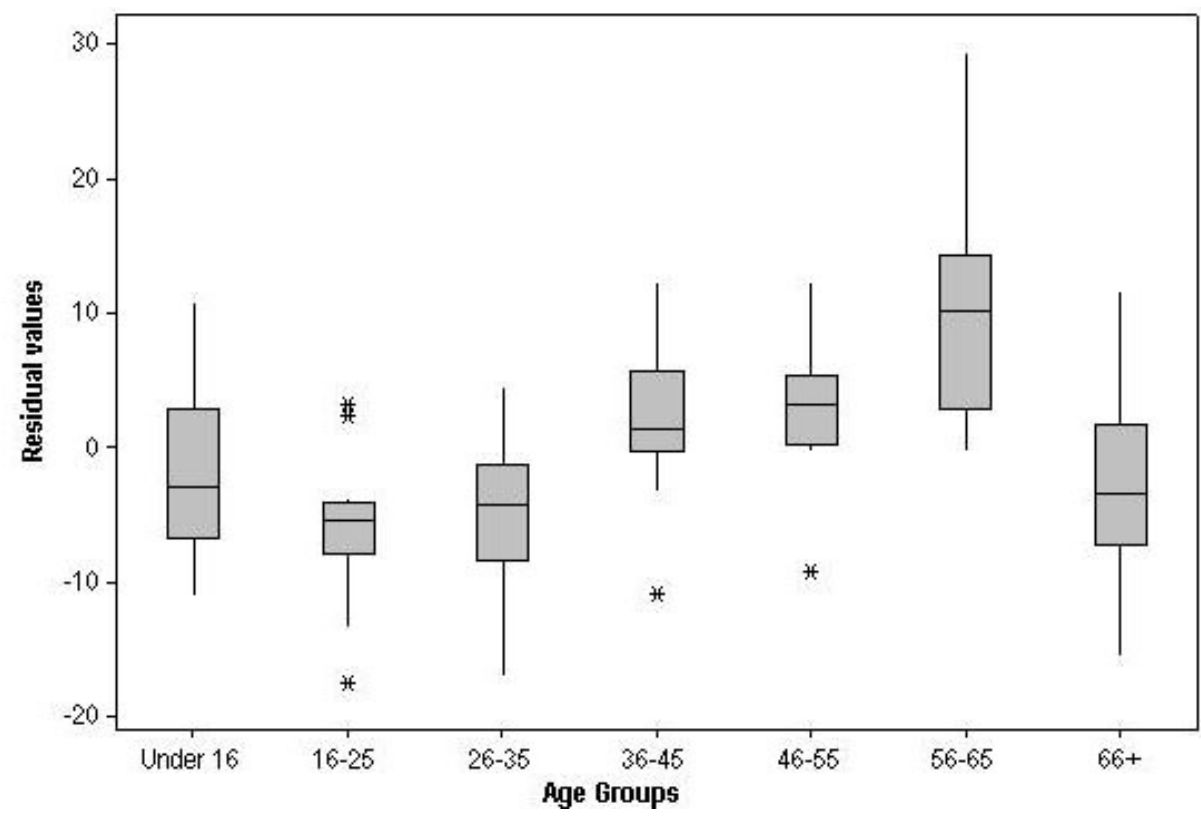

recreation and the natural environment (Pergams and Zaradic 2006) or of the 56-65 age group having greater leisure time and disposable income than younger groups as well as better health than the 66+ age group (Payne et al. 2002). This bias in outdoor visitation rates applies over and above the existing trend towards an aging rural population in the UK (Carpenter 2005, Commission for Rural Communities 2007), because it persists when studying the residuals (observed minus expected values) and accounting for the composition of the local population.

Currently, just one third of adults visit the countryside in England (Natural England 2006). Given that protected areas in the UK do not appear to be benefiting a broad sector of society in terms of recreational usage, the critical policy question becomes what steps, if any, need to be taken to improve the distribution of this direct-use benefit. The government agency responsible for managing these protected areas has committed to engaging more of the population in countryside recreation and, along with other agencies, to broadening the diversity of those visitors (Black Environment Network 2003, Edwards and Weldon 2006).
Various strategies could be employed to increase the diversity of individuals enjoying recreation benefits from protected areas. Efforts to develop equitable access to the environment could favor a location-based strategy aimed at ensuring that protected areas are located sufficiently close to various communities. This strategy could involve establishing additional designated areas, a process that could be guided by a relatively straightforward extension of recent planning tools (Ruliffson et al. 2003, Önal and Yanprechaset 2007) to encompass social diversity indices. However, our results suggest that such an approach on its own would do little to even out the distribution of actual benefits from recreation, because systematic biases still remained when we compared the diversity of visitors at the local scale.

In addition to improving access, we anticipate that a more proactive approach will be required to engage people with protected areas and achieve a broader diversity of beneficiaries. Efforts to attract a greater diversity of people to sites also need to reflect the heterogeneities of different sectors of society, each of which has different recreational preferences, needs, and aspirations for nature (Baas et al. 1993, Payne et al. 2002, Sasidharan 2007). 
Table 3. Results of individual site correlations of Mosaic data with reference populations (using Pearson's correlation coefficient and Spearman's rank correlation as appropriate).

Using Pearson's correlation coefficient for sites where data was normally distributed:

\begin{tabular}{|c|c|c|c|c|c|c|c|c|}
\hline & \multicolumn{2}{|c|}{$\begin{array}{c}25^{\text {th }} \text { percentile } \\
\text { of distance traveled }\end{array}$} & \multicolumn{2}{|c|}{$\begin{array}{l}50^{\text {th }} \text { percentile } \\
\text { of distance traveled }\end{array}$} & \multicolumn{2}{|c|}{ Yorkshire } & \multicolumn{2}{|c|}{ UK } \\
\hline & $r^{2}$ & $P$ & $r^{2}$ & $P$ & $r^{2}$ & $P$ & $r^{2}$ & $P$ \\
\hline Brockadale & 0.77 & 0.00 & 0.71 & 0.00 & 0.32 & 0.11 & 0.78 & 0.00 \\
\hline $\begin{array}{l}\text { Cow and Calf } \\
\text { Rocks }\end{array}$ & 0.41 & 0.03 & 0.26 & 0.11 & 0.59 & 0.00 & 0.48 & 0.02 \\
\hline Denaby Ings & 0.94 & 0.00 & 0.92 & 0.00 & 0.67 & 0.05 & 0.59 & 0.07 \\
\hline $\begin{array}{l}\text { Fairburn and } \\
\text { Newton Ings }\end{array}$ & 0.55 & 0.03 & 0.63 & 0.02 & 0.60 & 0.01 & 0.42 & 0.03 \\
\hline Filey Brigg & 0.03 & 0.94 & 0.00 & 0.91 & 0.03 & 0.66 & 0.29 & 0.14 \\
\hline Flamborough Head & 0.08 & 0.47 & 0.44 & 0.05 & 0.59 & 0.02 & 0.57 & 0.02 \\
\hline Potteric Carr & 0.27 & 0.12 & 0.32 & 0.09 & 0.14 & 0.29 & 0.48 & 0.03 \\
\hline Sandall Beat & 0.56 & 0.05 & 0.70 & 0.02 & 0.45 & 0.10 & 0.65 & 0.03 \\
\hline Skipwith Common & 0.74 & 0.01 & 0.52 & 0.04 & 0.34 & 0.10 & 0.12 & 0.36 \\
\hline Sprotbrough Flash & 0.38 & 0.19 & 0.57 & 0.05 & 0.88 & 0.00 & 0.79 & 0.01 \\
\hline Spurn Head & 0.41 & 0.03 & 0.47 & 0.02 & 0.50 & 0.02 & 0.56 & 0.01 \\
\hline
\end{tabular}

Using Spearman's rank correlations for sites where data did not meet assumptions of normality:

\begin{tabular}{lcccccccc} 
& $r_{\mathrm{s}}$ & $P$ & $r_{\mathrm{s}}$ & $P$ & $r_{\mathrm{s}}$ & $P$ & $r_{\mathrm{s}}$ & $P$ \\
\hline Tophill Low & 0.63 & 0.04 & 0.68 & 0.02 & 0.85 & 0.00 & 0.41 & 0.21 \\
$\begin{array}{l}\text { Forge Valley } \\
\text { Woods }\end{array}$ & 0.65 & 0.03 & 0.78 & 0.01 & 0.45 & 0.16 & 0.48 & 0.13 \\
\hline
\end{tabular}


Fig. 6. Scatter plot showing minimum $r^{2}$ values for Mosaic groups by site $(n=11)$ for the $25^{\text {th }}$ and $50^{\text {th }}$ percentiles of distance traveled against maximum $r^{2}$ values from Yorkshire and the UK. Results of aggregated site correlations against Yorkshire and the UK (all sites) are shown for reference. Sites situated below the line show the effects of localization.

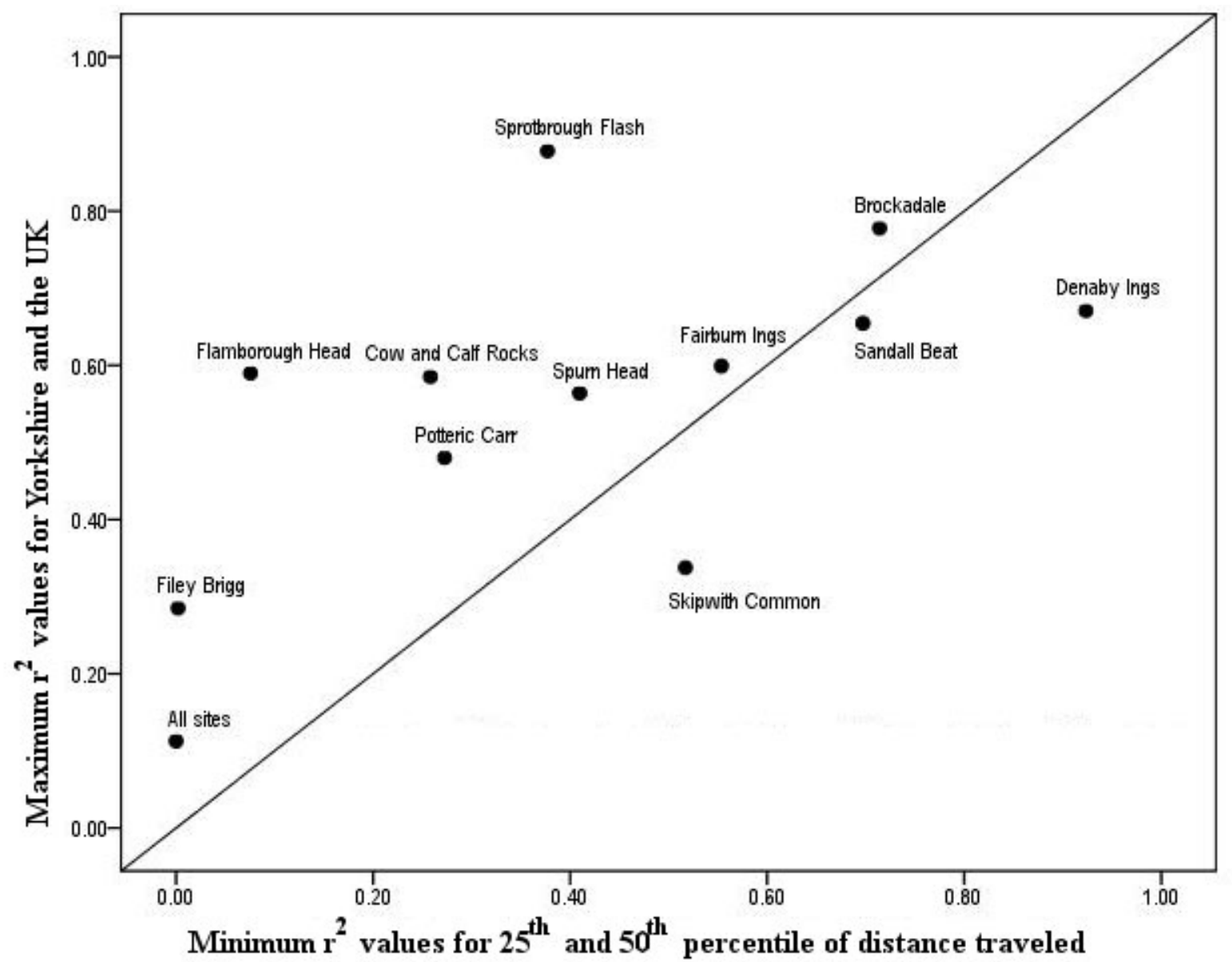

It could be debated whether SSSIs provide a suitable policy vehicle for broadening the diversity of beneficiaries of countryside ecosystem services, given that these SSSI areas were originally designated for very different reasons. However, SSSIs could perhaps always be considered part of the solution in the UK, because these areas are unlikely to be delisted. Indeed, policy makers will instead tend to favor bundled solutions that build on existing conservation efforts and yet can deliver multiple policy goals (e.g., conservation as well as recreation). In addition, nearly $55 \%$ of access land in England under the Countryside and Rights of
Way (CRoW) Act of 2000 is designated as SSSIs (Bathe 2007). Even before the introduction of CRoW, SSSIs experienced an estimated 370 million visits per annum (Drewitt 2007).

SSSIs are under a mix of public, private, and NGO ownership, and regulatory requirements for these sites are prohibitive rather than proactive. However, conservation payment schemes for landowners (agrienvironment schemes) also fall under the aegis of Natural England, the agency responsible for managing SSSIs. Such schemes are intended to provide incentives for landowners to provide the 
types of goods and services from the countryside that the public wish to see, and specific provisions are included for encouraging improved recreational access to sites.

Our results have direct implications for those trying to map, evaluate, and plan for the provision of ecosystem services. To date, such studies have tended to emphasize remote data (e.g., Chan et al. 2006) and ecosystem service value flows (e.g., Troy and Wilson 2006). Efforts at assessing recreation benefits using only remote data often default to estimating access measures based simply on household location (Önal and Yanprechaset 2007). However, our results show that such estimates will give an inaccurate picture of recreation benefits, because only a biased subset of individuals and households participate in recreation, and those that do participate will travel very different distances to reach particular sites. Similarly, our sites were found to be heterogeneous in their visitor distributions; some serve very local visitors and others serve populations from much broader areas.

Studies into the interactions of human recreation and protected areas have frequently viewed such contact as a potential threat to biodiversity (e.g., Yalden and Yalden 1990, Taylor and Knight 2003, George and Crooks 2006). However, ecosystem service approaches to conservation are more synergistic (Balvanera et al. 2001). Such approaches recognize that long-term conservation goals will only be met if broad public support can be maintained for habitat conservation measures (such as preserving protected areas). Developing public support requires engaging more people with the natural environment, for example through recreation, and making them aware of the many diverse ways that ecosystems support and enhance their lives. However, our study has shown that the sector of society that currently benefits from protected areas through recreation is unrepresentative of the overall population of the UK.

Evidence from many disciplines, including psychology, biology, ecology, environmental health, medicine, and public health, shows that contact with the natural environment can improve both the physical and the mental health and wellbeing of the population (Fuller et al. 2007, Pretty et al. 2007). Therefore, increasing the diversity of people visiting protected areas is important not just for conservation and its support but also for the health of the visitors, which creates opportunities for improving public health (St Leger 2007).

To achieve wider societal engagement with protected area conservation and nature in general will require proactive policy measures. These measures should focus on improving accessibility to protected areas and attracting less privileged groups to these sites, where they can experience the considerable benefits that nature recreation can provide (Jackson 2003, Chiesura 2004).

Responses to this article can be read online at: http://www.ecologyandsociety.org/voll5/iss3/art19/ responses/

\section{Acknowledgments:}

This work resulted from a studentship funded as part of the UK Population Biology Network (UKPopNet) and funded by the Natural Environment Research Council (Agreement R8-H12-01 \& NER/S/ R/2005/13940) and Natural England. We thank Experian Business Strategies Divisionfor providing access to Mosaic UK, and we thank the managers and owners of the sites included in this study. Many thanks to R. O'Connor, R. York, and L. Inglis for their work as field assistants. Our thanks to Z. G. Davies, S. F. Jackson, and I. S. Fishburn for comments. K. J. Gaston was supported by the Royal Society and the Leverhulme Trust.

\section{LITERATURE CITED}

Baas, J. M., A. Ewert, and D. J. Chavez. 1993. Influence of ethnicity in recreation and natural environment use patterns: managing recreation sites for ethnic and racial diversity. Environmental Management 17:523-529.

Balmford, A., A. Bruner, P. Cooper, R. Costanza, S. C. Farber, R. E. Green, M. Jenkins, P. Jefferiss, V. Jessamy, J. Madden, K. Munro, N. Myers, S. Naeem, J. Paavola, M. Rayment, S. Rosendo, J. Roughgarden, K. Trumper, and R. K. Turner. 2002. Economic reasons for conserving wild nature. Nature 297:950-953. 
Balvanera, P., G. C. Daily, P. R. Ehrlich, T. H. Ricketts, S. A. Bailey, S. Kark, C. Kremen, and H. Pereira. 2001. Conserving biodiversity and ecosystem services. Science 291:2047.

Barbosa, O., J. A. Tratalos, P. R. Armsworth, R. G. Davies, R. A. Fuller, P. Johnson, and K. J. Gaston. 2007. Who benefits from access to green space? A case study from Sheffield, UK. Landscape and Urban Planning 83:187-195.

Bathe, G. 2007. Political and social drivers for access to the countryside: the need for research on birds and recreational disturbance. Ibis 149:3-8.

Bishop, K., A. Phillips, and L. M. Warren. 1997. Protected areas for the future: models from the past. Journal of Environmental Management 40:81-110.

Black Environment Network. 2003. Capturing richness: countryside visits by black and ethnic minority communities. The Countryside Agency, Cheltenham, UK. [online] URL: http://www.natura lengland.org.uk/Images/capturingrichnessfinaltcm2 -10023 tcm6-4017.pdf.

Booth, J. E., K. J. Gaston, and P. R. Armsworth. 2009. Biological Conservation 142:3196-3200.

Bowker, J. M., and V. R. Leeworthy. 1998. Accounting for ethnicity in recreation demand: a flexible count data approach. Journal of Leisure Research 30:64-78.

Brooks, T. M., M. L. Bakarr, T. Boucher, G. A. B. da Fonseca, C. Hilton-Taylor, J. M. Hoekstra, T. Moritz, S. Oliveri, J. Parrish, R. L. Pressey, A. S. L. Rodrigues, W. Sechrest, A. Attaterfield, W. Strahm, and S. N. Stuart. 2004. Coverage provided by the global protected-area system: is it enough? Bioscience 54:1081-1091.

Carpenter, G. I. 2005. Aging in the United Kingdom and Europe: a snapshot of the future? Journal of the American Geriatrics Society 53: S310-S313.

Carpenter, S. R., R. Defries, T. Dietz, H. A. Mooney, S. Polasky, W. V. Reid, and R. J. Scholes. 2006. Millennium Ecosystem Assessment: research needs. Science 314:257-258.

Chan K. M. A., M. R. Shaw, D. R. Cameron, E. C. Underwood, and G. C. Daily. 2006.
Conservation planning for ecosystem services. Public Library of Science (PLoS) Biology 4:2138-2152.

Chape, S., J. Harrison, M. Spalding, and I. Lysenko. 2005. Measuring the extent and effectiveness of protected areas as an indicator for meeting global biodiversity targets. Philosophical Transactions of the Royal Society B: Biological Sciences 306:443-455.

Chiesura, A. 2004. The role of urban parks for the sustainable city. Landscape and Urban Planning 68:129-138.

Commission for Rural Communities. 2007. The state of the countryside 2007. [online] URL: http:// ruralcommunities.gov.uk/files/socr2007-fullreport. pdf.

Countryside Agency. 2005. The Countryside Agency diversity review and recommended outline action plan. [online] URL: http://www.naturalengl and.org.uk/Images/DEFRA\%20DR\%20and\%200utline\% 20Action\%20Plan\%20with\%20annexes\%2016\%20Dec\% 2005 tcm2-28630 tcm6-3674.doc.

Drewitt, A. L. 2007. Birds and recreational disturbance. Ibis 149:1-2.

Dunk, J. R., W. J. Zielinski, and H. W. Welsh, Jr. 2006. Evaluating reserves for species richness and representation in northern California. Diversity and Distributions 12:434-442.

Edwards, D., and S. Weldon. 2006. Race equality and the Forestry Commission. Forest Research, Forestry Commission, UK. [online] URL: http://w ww.forestry.gov.uk/pdf/FR290807 RESFinalReport. pdf/\$FILE/FR290807 RESFinalReport.pdf.

Eigenbrod, F., B. J. Anderson, P. R. Armsworth, A. Heinemeyer, S. E. Jackson, M. Parnell, C. D. Thomas, and K. J. Gaston. 2009. Ecosystem service benefits of contrasting conservation strategies in a human-dominated region. Proceedings of the Royal Society B: Biological Sciences 276:2903-2911.

English Nature. 2003. England's best wildlife and geological sites. The condition of Sites of Special Scientific Interest in England in 2003. English Nature, Peterborough, UK. 
Fa, J. E., Juste, J., Burn, R. W. and Broad, G. 2002. Bushmeat consumption and preferences of two ethnic groups in Bioko Island, West Africa. Human Ecology 30:397-416.

Farr, M., and R. Webber. 2001. MOSAIC: from an area classification system to individual classification. Journal of Targeting, Measurement and Analysis for Marketing 10:55-65.

Floyd, M. F., and C. Y. Johnson. 2002. Coming to terms with environmental justice in outdoor recreation: a conceptual discussion with research implications. Leisure Sciences 24:59-77.

Fuller, R. A., K. N. Irvine, P. Devine-Wright, P. H. Warren, and K. J. Gaston. 2007. Psychological benefits of greenspace increase with biodiversity. Biology Letters 3:390-394.

Fuller, R. A., P. H. Warren, P. R. Armsworth, O. Barbosa, and K. J. Gaston. 2008. Garden bird feeding predicts the structure of urban avian assemblages. Diversity and Distributions 14:131-137.

Gaston, K. J., K. Charman, S. F. Jackson, P. R. Armsworth, A. Bonn, R. Briers, C. S. Q. Callaghan, R. Catchpole, J. Hopkins, W. E. Kunin, J. Latham, J. Opdam, R. Stoneham, D. A. Stroud, and R. Tratt. 2006. The ecological effectiveness of protected areas: the United Kingdom. Biological Conservation 132:78-87.

George, S. L., and K. R. Crook. 2006. Recreation and large mammal activity in an urban nature reserve. Biological Conservation 133:107-117.

Gómez, E. 2002. The ethnicity and public recreation participation model. Leisure Sciences 24:123-142.

Harris, R., P. Sleight, and R. Webber. 2005. Geodemographics, GIS and neighbourhood targeting. John Wiley and Sons, Chichester, England.

Hein, L., K. van Koppen, R. S. de Groot, and E. C. van Ierland. 2006. Spatial scales, stakeholders and the valuation of ecosystem services. Ecological Economics 57:209-228.

Ho, C., V. Sasidharan, W. Elmendorf, F. K. Willits, A. Graefe, and G. Godbey. 2005. Gender and ethnic variations in urban parks preferences, visitation and perceived benefits. Journal of Leisure Research 37:281-307.

Holdgate, M. W. 1992. Protected landscapes - an overview. Pages 7-12 in Protected landscapes where next? Report of the 1992 Conference of National Park Authorities. Countryside Commission/ Countryside Commission for Wales Protected Landscapes. Countryside Commission, Cheltenham, UK.

Ingraham, M. W., and S. G. Foster. 2008. The value of ecosystem services provided by the US National Wildlife Refuge System in the contiguous US. Ecological Economics 67:608-618.

Jackson, L. E. 2003. The relationship of urban design to human health and condition. Landscape and Urban Planning 64:191-200.

Kolstad, C. D. 2000. Environmental Economics. Oxford University Press, New York, New York, USA.

Krenichyn, K. 2006. 'The only place to go and be in the city': women talk about exercise, being outdoors, and the meanings of a large urban park. Health and Place 12:631-643.

Lee, J. H., and D. Scott. 2001. Structural inequalities in outdoor recreation participation: a multiple hierarchy stratification perspective. Journal of Leisure Research 33:427-449.

Mehta, A., and L. Bondi. 1999. Embodied discourse: on gender and fear of violence. Gender, Place and Culture 6:67-84.

Millennium Ecosystem Assessment. 2005. Living beyond our means: natural assets and human wellbeing. World Resources Institute, Washington, D. C., USA. [online] URL: http://www.millenniumass essment.org/documents/document.429.aspx.pdf.

Naidoo, R., and T. H. Ricketts. 2006. Mapping the economic costs and benefits of conservation. Public Library of Science (PLoS) Biology 4(11):e360. doi:10.1371/journal.pbio.0040360.

National Audit Office. 2008. Natural England's role in improving sites of Special Scientific Interest. The Stationery Office (TSO), London, UK. 
Natural England. 2006. Strategic Direction (2006-2009). English Nature, Peterborough, UK.

Oates, W. E. 2006. The many faces of the Tiebout model. Pages 21-45 in W. A. Fischel, editor. The Tiebout model at fifty. Lincoln Institute of Land Policy, Cambridge, MA, USA.

Önal, H., and P. Yanprechaset. 2007. Site accessibility and prioritization of nature reserves. Ecological Economics 60:763-773.

Payne, L. L., A. J. Mowen, and E. Orsega-Smith. 2002. An examination of park preferences and behaviours among urban residents: the role of residential location, race and age. Leisure Sciences 24:191-198.

Pergams, O. R. W., and P. A. Zaradic. 2006. Is love of nature in the US becoming a love of electronic media? 16-year downtrend in national park visits explained by watching movies, playing video games, internet use and oil prices. Journal of Environmental Management 80:387-393.

Pretty, J., J. Peacock, R. Hine, M. Sellens, N. South, and M. Griffin. 2007. Green exercise in the UK countryside, effects on health and psychological well-being, and implications for policy and planning. Journal of Environmental Planning and Management 50:211-231.

Reed, S. E. and A. M. Merenlender. 2008. Quiet, nonconsumptive recreation reduces protected area effectiveness. Conservation Letters 1:146-154.

Ruliffson, J. A., R. G. Haight, P. H. Gobster, and F. R. Homans. 2003. Metropolitan natural area protection to maximize public access and species representation. Environmental Sciences Policy 6:291-299.

Sasidharan, V. 2007. Special issue introduction: understanding recreation and the environment within the context of culture. Leisure Sciences 24:1-11.

Scarpa, R., W. G. Hutchinson, S. M. Chilton, and J. Buongiorno. 2000. Importance of forest attributes in the willingness to pay for recreation: a contingent valuation study of Irish forests. Forest Policy and Economics 1:315-329.
Shaw, S. M. 1994. Gender, leisure, and constraint: towards a framework for the analysis of women's leisure. Journal of Leisure Research 26:8-22.

Shores, K. A., D. Scott, and M. F. Floyd. 2007. Constraints to outdoor recreation: a multiple hierarchy stratification perspective. Leisure Sciences 29:227-246.

St Leger, L. 2003. Health and nature-new challenges for health promotion. Health Promotion International 18:173-175.

Sutherland, W. J., S. Armstrong-Brown, P. R. Armsworth, T. Brereton, J. Brickland, C. D. Campbell, D. E. Chamberlain, A. I. Cooke, N. K. Dulvy, N. R. Dusic, M. Fitton, R. P. Freckleton, H. C. Godfray, N. Grout, H. J. Harvey, C. Hedley, J. J. Hopkins, N. B. Kift, J. Kirby, W. E. Kunin, D. W. MacDonald, B. Markee, M. Naura, A. R. Neale, T. Oliver, D. Osborn, A. S. Pullin, M. E. A. Shardlow, D. A. Showler, P. L. Smith, R. J. Smithers, J. L. Solandt, J. Spencer, C. J. Spray, C. D. Thomas, J. Thompson, S. E. Webb, D. W. Yalden, and A. R. Watkinson. 2006. The identification of 100 ecological questions of high policy relevance in the UK. Journal of Applied Ecology 43:617-627.

Tarrant, M. A., and H. K. Cordell. 1999. Environmental justice and the spatial distribution of outdoor recreation: an application in geographical information systems. Journal of Leisure Research 31:18-34.

Taylor, A. R., and R. L. Knight. 2003. Wildlife responses to recreation and associated visitor perceptions. Ecological Applications 13:951-963.

Tiebout, C. M. 1956. A pure theory of local expenditures. Journal of Political Economy 64:416-424.

Troy, A., and M. A. Wilson. 2006. Mapping ecosystem services: practical challenges and opportunities in linking GIS and value transfer. Ecological Economics 60:435-449.

Virden, R.J., and G. J. Walker. 1999. Ethnic/racial and gender variation among meanings given to, and preferences for, the natural environment. Leisure Sciences 21:219-239. 
Webber, R. 1985. The use of census-derived classifications in the marketing of consumer products in the United Kingdom. Journal of Economic and Social Measurement 13:113-124.

Webber, R. 2004. Designing geo-demographic classification to meet contemporary business needs. Interactive Marketing 5:219-237.

Wesley, J. K., and E. Gaarder. 2004. The gendered "nature" of the urban outdoors: women negotiating fear of violence. Gender and Society 18:645-663.

Williamson, T., D. I. Ashby, and R. Webber. 2005. Young offenders, schools and the neighbourhood: a new approach to data-analysis for community policing. Journal of Community and Applied Social Psychology 15:203-228.

Yalden, P. E., and D. W. Yalden. 1990. Recreational disturbance of breeding golden plovers Pluvialis apricarius. Biological Conservation 51:243-262. 
APPENDIX 1. Questionnaire used to determine who benefits from recreational use of protected areas (a subset of the full questionnaire).

How many people in your group are in each age category? Please write the number next to the category.

$\begin{array}{lrrrrr}\text { Under } 16 & 16-25 & 26-35 & 36-45 & 46-55 & 56-65\end{array}$

To help understand where visitors have come from, it is very useful to know your postcode. Please note it will not be used to contact you: each postcode applies to about 20 houses and does not identify you individually.

Postcode:

Please give details of your group.

Number of females: Number of males:

The ethnic group that best describes you is (please tick a box):

White

Black - Caribbean

Black - African

Which activities have you done here today?

Walking

Dog walking

Picnic

Bangladeshi

Black - other group

Bird watching

$$
\text { Cycling }
$$


APPENDIX 2. One-way chi square tests for gender at individual site level vs. four reference populations.

\begin{tabular}{|c|c|c|c|c|c|c|c|c|}
\hline & \multicolumn{2}{|c|}{$25^{\text {th }}$ percentile } & \multicolumn{2}{|c|}{$50^{\text {th }}$ percentile } & \multicolumn{2}{|c|}{ Yorkshire } & \multicolumn{2}{|c|}{ UK } \\
\hline & Male & $P$ & Male & $P$ & Male & $P$ & Male & $P$ \\
\hline Brockadale & 3.59 & $>0.05$ & 4.01 & $<0.05$ & 3.47 & $>0.05$ & 3.52 & $>0.05$ \\
\hline Cow and Calf Rocks & 1.86 & $>0.05$ & 1.80 & $>0.05$ & 1.52 & $>0.05$ & 1.42 & $>0.05$ \\
\hline Denaby Ings & 5.21 & $<0.05$ & 5.06 & $<0.05$ & 5.10 & $<0.05$ & 4.95 & $<0.05$ \\
\hline $\begin{array}{l}\text { Fairburn and Newton } \\
\text { Ings }\end{array}$ & 2.74 & $>0.05$ & 2.77 & $>0.05$ & 2.66 & $>0.05$ & 2.56 & $>0.05$ \\
\hline Filey Brigg & 0.52 & $>0.05$ & 0.52 & $>0.05$ & 0.50 & $>0.05$ & 0.45 & $>0.05$ \\
\hline Flamborough Head & 0.01 & $>0.05$ & 1.12 & $>0.05$ & 0.00 & $>0.05$ & 0.00 & $>0.05$ \\
\hline Forge Valley Woods & 0.03 & $>0.05$ & 0.04 & $>0.05$ & 0.00 & $>0.05$ & 0.00 & $>0.05$ \\
\hline Potteric Carr & 3.44 & $>0.05$ & 3.48 & $>0.05$ & 3.43 & $>0.05$ & 3.32 & $>0.05$ \\
\hline Sandall Beat & 2.76 & $>0.05$ & 2.68 & $>0.05$ & 2.47 & $>0.05$ & 2.38 & $>0.05$ \\
\hline Skipwith Common & 0.01 & $>0.05$ & 0.00 & $>0.05$ & 0.00 & $>0.05$ & 0.00 & $>0.05$ \\
\hline Spurn Head & 0.82 & $>0.05$ & 0.85 & $>0.05$ & 0.86 & $>0.05$ & 0.78 & $>0.05$ \\
\hline Sprotbrough Flash & 0.12 & $>0.05$ & 0.09 & $>0.05$ & 0.10 & $>0.05$ & 0.09 & $>0.05$ \\
\hline Tophill Low & 1.13 & $>0.05$ & 1.13 & $>0.05$ & 1.12 & $>0.05$ & 1.08 & $>0.05$ \\
\hline
\end{tabular}


APPENDIX 3. One-way chi square tests for ethnicity at individual site level vs. four reference populations.

\begin{tabular}{|c|c|c|c|c|c|c|c|c|}
\hline & \multicolumn{2}{|c|}{$25^{\text {th }}$ percentile } & \multicolumn{2}{|c|}{$50^{\text {th }}$ percentile } & \multicolumn{2}{|c|}{ Yorkshire } & \multicolumn{2}{|c|}{ UK } \\
\hline & $\begin{array}{l}\text { Ethnic } \\
\text { minority }\end{array}$ & $P$ & $\begin{array}{l}\text { Ethnic } \\
\text { minority }\end{array}$ & $P$ & $\begin{array}{l}\text { Ethnic } \\
\text { minority }\end{array}$ & $P$ & $\begin{array}{l}\text { Ethnic } \\
\text { minority }\end{array}$ & $P$ \\
\hline Brockadale & 0.96 & $>0.05$ & 1.20 & $>0.05$ & 4.76 & $<0.05$ & 5.76 & $<0.05$ \\
\hline Cow and Calf Rocks & 0.97 & $>0.05$ & 12.1 & $<0.01$ & 0.156 & $>0.05$ & 0.87 & $>0.05$ \\
\hline Denaby Ings & 1.13 & $>0.05$ & 1.15 & $>0.05$ & 4.36 & $<0.05$ & 5.20 & $<0.05$ \\
\hline $\begin{array}{l}\text { Fairburn and Newton } \\
\text { Ings }\end{array}$ & 1.16 & $>0.05$ & 1.90 & $>0.05$ & 4.37 & $<0.05$ & 5.28 & $<0.05$ \\
\hline Filey Brigg & 2.18 & $>0.05$ & 3.71 & $>0.05$ & 5.67 & $<0.05$ & 6.86 & $<0.01$ \\
\hline Flamborough Head & 2.39 & $>0.05$ & 3.99 & $<0.05$ & 9.25 & $<0.01$ & 11.20 & $<0.01$ \\
\hline Forge Valley Woods & 1.70 & $>0.05$ & 1.8 & $>0.05$ & 5.21 & $<0.05$ & 6.31 & $<0.05$ \\
\hline Potteric Carr & 3.67 & $>0.05$ & 2.76 & $>0.05$ & 4.11 & $<0.05$ & 4.97 & $<0.05$ \\
\hline Sandall Beat & 2.40 & $>0.05$ & 2.40 & $>0.05$ & 4.17 & $<0.05$ & 5.05 & $<0.05$ \\
\hline Skipwith Common & 0.63 & $>0.05$ & 1.34 & $>0.05$ & 4.69 & $<0.05$ & 5.68 & $<0.05$ \\
\hline Spurn Head & 3.73 & $>0.05$ & 5.98 & $<0.05$ & 7.49 & $<0.01$ & 9.45 & $<0.01$ \\
\hline Sprotbrough Flash & 1.94 & $>0.05$ & 2.35 & $>0.05$ & 3.91 & $<0.05$ & 4.74 & $<0.05$ \\
\hline Tophill Low & 0.70 & $>0.05$ & 0.99 & $>0.05$ & 2.35 & $>0.05$ & 2.84 & $>0.05$ \\
\hline
\end{tabular}

